\title{
Revisão Literária em Teses e Dissertações sobre Cotas na Pós-graduação da UFPB
}

\author{
ALBUQUERQUE, Larissa Cavalcanti de ${ }^{1}$
}

\section{RESUMO}

As ações afirmativas iniciaram no Brasil em contextos locais, sendo o pioneiro nessa política o estado do Rio de Janeiro, somente em 2012, com a Lei 12.711 que todas as universidades passaram a adotar a política de reserva de vagas. $O$ artigo possui o objetivo geral de realizar a revisão literária de teses e dissertações defendidas na UFPB sobre ações afirmativas e como objetivos específicos, ressaltamos: identificar teses e dissertações defendidas por área do conhecimento que versem sobre ações afirmativas; realizar levantamento do percurso metodológico e refletir sobre os principais assuntos que aparecem nos trabalhos. A relevância desse tipo de estudo encontra-se em fornecer um panorama das pesquisas que já foram realizadas e as lacunas que poderão tornar-se problemas de pesquisa futuros, o que contribui para o processo de construção do conhecimento e auxilia pesquisadores na definição de objetivos para pesquisa.

Democratização da educação superior. Ações afirmativas. Acesso e Permanência.

\section{Literary review on theses and dissertations on quotas in the postgraduation of UFPB}

\section{ABSTRACT}

As affirmative actions initiated in Brazil in local contexts, being the pioneer in this policy in the state of Rio de Janeiro, only in 2012, with Law 12.711 that all universities study to adopt a policy of reserve of places. The article has the general objective of carrying out a literary review of theses and dissertations defended at UFPB on affirmative actions and as objectives, we emphasize: to identify theses and dissertations defended by the area of knowledge that deals with affirmative actions; conduct a survey of the methodological path and reflect on the main issues that appear in the works. The relevance of this type of study lies in providing an overview of the research that has already been carried out and the gaps that may cause future research problems, which contributes to the

\footnotetext{
${ }^{1}$ Doutoranda do Programa de Pós-Graduação em Educação da UFPB. Email laalbuquerque13@hotmail.com. Lattes: http://lattes.cnpq.br/7167318693091247. Orcid: http://orcid.org/0000-0001-8439-3195.
}

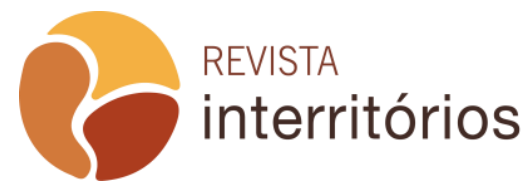


process of building knowledge and assisting researchers in defining research objectives.

\section{Democratization of higher education. Affirmative actions. Access and}

Permanence.

\section{Revisión literaria de tesis y disertaciones sobre cuotas en el programa de posgrado de la UFPB}

\section{RESUMEN}

Las acciones afirmativas se iniciaron en Brasil en contextos locales, y el estado de Río de Janeiro fue pionero en esta política, solo en 2012, con la Ley 12.711 que todas las universidades comenzaron a adoptar la política de reserva de becas. El artículo tiene como objetivo general realizar una revisión literaria de las tesis y disertaciones defendidas en la UFPB sobre acciones afirmativas y como objetivos específicos, destacamos: identificar tesis y disertaciones defendidas por áreas de conocimiento que abordan las acciones afirmativas; realizar un relevamiento de la trayectoria metodológica y reflexionar sobre los principales temas que aparecen en los trabajos. La relevancia de este tipo de estudios tiene que ver con la posibilidad de ofrecer una visión general de la investigación que ya se ha realizado y las brechas que podrán convertirse en problemas de investigación futuros, lo que contribuye al proceso de construcción de conocimiento y ayuda a los investigadores en la definición de objetivos para investigar.

Democratización de la educación superior. Acciones afirmativas. Acceso y permanencia.

\section{Revisione letteraria di tesi e dissertazioni sulle tasse nel corso di laurea UFPB}

\section{SOMMARIO}

Le azioni affermative sono iniziate in Brasile in contesti locali, e lo stato di Rio de Janeiro è stato un pioniere in questa politica, solo nel 2012, con la legge 12,711 che tutte le università hanno iniziato ad adottare la politica di prenotazione delle borse di studio. L'obiettivo generale dell'articolo è quello di effettuare una revisione letteraria delle tesi e dissertazioni difese all'UFPB sulle azioni affermative e come obiettivi specifici, si evidenziano: identificare tesi e dissertazioni difese da aree di conoscenza che affrontano azioni affermative; effettuare una ricognizione del percorso metodologico e riflettere sui temi principali che compaiono nei lavori. La rilevanza di questo tipo di studio ha a che fare con la possibilità di offrire una panoramica della ricerca che è già stata effettuata e delle lacune che possono diventare problemi di ricerca futuri, che contribuisce al processo di costruzione della conoscenza e aiuta a ricercatori nella definizione degli obiettivi di ricerca.

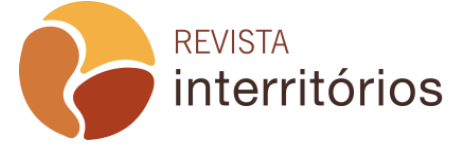

Interritórios | Revista de Educação

Universidade Federal de Pernambuco, Caruaru, BRASIL | V.6 N.12 [2020] 
Democratizzazione dell'istruzione superiore. Azioni affermative. Accesso e permanenza.

\section{INTRODUÇÃO}

O artigo possui a finalidade de realizar uma revisão literária em teses e dissertações defendidas entre os anos 2008-2017 na UFPB. Possui como objetivos específicos: identificar teses e dissertações defendidas por área do conhecimento que versem sobre ações afirmativas; realizar levantamento do percurso metodológico e refletir sobre os principais assuntos que aparecem nos trabalhos.

A relevância da temática encontra-se na discussão sobre acesso e permanência de grupos sub-representados na educação superior pública, como mecanismo de justiça social e equidade, para a análise das produções, recorremos aos estudos de Marília Costa Morosini (2009), Feres Júnior e Daflon (2014), Nancy Fraser (2008) e Bordieu e Passeron (2015), que nos ajudaram nesta incursão teórica.

Inicialmente situamos a problemática das ações afirmativas no contexto de democratização da educação superior, com a discussão de categorias teóricas de equidade, justiça social e democratização pelas as autoras Morosini (2009), Nancy Fraser (2008) e Chauí (2003). No segundo momento tratamos sobre os caminhos da pesquisa e seus achados, resultados, ao final colocamos nossas considerações e as referências norteadoras do estudo.

\section{Ações afirmativas na educação superior pública: equidade e justiça social}

As ações afirmativas iniciaram no contexto local no estado do Rio de Janeiro em 2002, tendo amplitude nacional em 2012 com a Lei no 12.711, fruto do processo de luta dos movimentos sociais. Não temos a intenção de realizar uma historiografia do processo de cotas nas universidades, mas sim realizar a revisão literária, conforme objetivos elencados, no intuito de refletir as ações afirmativas numa perspectiva de política que contribui para democratização da universidade, para equidade e justiça social em nossa sociedade.

Dados do Censo da Educação Superior (2018) apontam que 87,9 \% das instituições da educação superior são privadas, esse processo de expansão e oferta de vagas, não significa democratização do acesso à educação superior, já que a compreensão do processo de democratização estar fortemente ligada, a incluir com qualidade, ofertando uma educação ancorada nos pilares de REVISTA Interritórios | Revista de Educação 
ensino, pesquisa e extensão. Vivemos tempos de expansão da educação superior, seja por meio da diversificação de instituições, como por programas federais e pelos financiamentos estudantis.

No contexto de democratização do acesso, a expansão do sistema de educação superior público processou-se associado às políticas de inclusão social, denominadas também de ações afirmativas. O debate da temática inclusão social sob a perspectiva das ações afirmativas como um processo de reparação social, que objetiva incluir minorias, historicamente excluídas do sistema de educação superior, ganha espaço nessa discussão em que emerge as categorias, como: democratização, equidade e justiça social, o que torna pertinente a discussão conceitual das referidas categorias, a fim de que possamos entender em que bases teóricas se assentam a produção acadêmica acerca das políticas de cotas.

No Brasil, as ações afirmativas seguem orientações internacionais, como a da UNESCO (2016), que aconselha a adoção de uma nova visão de educação superior, baseada na igualdade de acesso, fundamentada no mérito e na reorientação da conexão da educação superior com os outros níveis educacionais. Recomenda à facilitação do acesso de grupos menos favorecidos, principalmente, a promoção do acesso das mulheres, diversificando, assim, a educação superior como opção para ampliar o acesso de grupos excluídos. (BORGES, 2011a).

O debate sobre o acesso de pessoas negras, pardas, quilombolas, pessoas com deficiência, dentre outros grupos sub-representados na universidade ganha notoriedade com o deslocamento do entendimento de universidade para a formação de elites, para local de formação social, como aponta Feres Júnior e Daflon (2014, p. 31):

Concebida até então prioritariamente como um lugar de formação de quadros de elite que contribuiriam para 0 desenvolvimento nacional, a universidade passou a ser cada vez mais vista como um espaço aberto a processos de democratização e instrumento de promoção de igualdade de oportunidades.

O suposto mérito que selecionava os melhores alunos para educação superior, se trata do acesso ao capital cultural e econômico nos termos de Bourdieu e Passeron (2015) a trajetória até o ingresso a universidade, dos filhos dos ricos, difere bastante do percurso escolar dos filhos dos pobres. Enquanto $o$ filho do rico estuda nos melhores colégios e possui acesso ao capital cultural, o filho do pobre termina o ensino médio cercado de diversas dificuldades, como a falta de uma dieta balanceada, ausência de serviços de saúde, precarização na 
política educacional no que diz respeito a ter acesso a material didático e infraestrutura das escolas.

A ação de movimentos sociais, particularmente do Movimento Negro, e de setores progressistas de nossa sociedade expôs esse contexto de flagrante desigualdade em que se realizava 0 vestibular no Brasil e tornou clara a necessidade de avançar a discussão sobre a democratização da universidade, no sentido de torná-la um instrumento de mobilidade social; um bem ao qual todos têm o direito de aspirar. (FERES JÚNIOR e DAFLON, 2014, p. 32).

Assim, as desigualdades são amplamente reproduzidas, culminando numa educação superior elitista e que não produz mudanças em termos de inclusão. Como afirma Bourdieu e Passeron (2015) os privilégios são transformados em méritos, dons e aptidões e o sistema funciona como legitimador desse processo, que é muito mais excludente e seletivo, do que inclusivo. Assim, nosso posicionamento de educação superior, visa à democratização da universidade, entendida como:

Se quisermos tomar a universidade pública sob uma nova perspectiva, precisamos começar exigindo, antes de tudo, que o Estado não tome a educação pelo prisma do gasto público e sim como investimento social e político, o que só é possível se a educação for considerada um direito e não um privilégio nem um serviço. [...] É pela destinação do fundo público aos direitos sociais que se mede a democratização do Estado e, com ela, a democratização da universidade. (CHAUÍ, 2003, p. 8).

As políticas de ações afirmativas, como oferta de políticas sociais buscam elevar a condição em que se encontram sujeitos em situação de vulnerabilidade social, no Brasil estas emergem no contexto da expansão do acesso a fim de minorar as desigualdades históricas. A igualdade de acesso e permanência embora garantida na Carta Magna de 1988 e na Lei de Diretrizes e Bases da Educação no 9.394/1996 não constitui uma igualdade real, tal igualdade fica tão somente no mundo abstrato das leis e não se configura no direito à educação superior de todos.

Nesse propósito Feres Júnior (2007) contribui na discussão afirmando que a igualdade não deve ser apenas um direito formal, mas uma igualdade de fato, que proporcione resultados, ora mudanças significativas no contexto da educação superior não se reduz apenas a teoria, mas a políticas democratizantes.

A universidade é uma instituição especializada na produção de conhecimento e desenvolvimento social, sua tarefa educacional consiste na

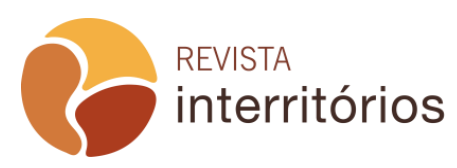

Interritórios | Revista de Educação

Universidade Federal de Pernambuco, Caruaru, BRASIL | V.6 N.12 [2020] 
melhoria da qualidade de vida dos sujeitos e, objetiva trabalhar na preparação, de forma integral, dos indivíduos para viverem em sociedade, colaborando na socialização e na continuação do patrimônio cultural. Compreende-se, assim, a presença de uma concepção de universidade multidimensional, não se restringindo ao aspecto econômico (BORGES, 2011a).

A universidade que almejamos prima pela inserção da diversidade que nos cerca, promove a pluralidade de ideias, formando sujeitos capazes de analisar criticamente a sociedade em que vivemos e principalmente emancipando para processos de transformação e de igualdade.

E essa igualdade está intimamente ligada à justiça social numa perspectiva bidimensional de reinvindicação redistributiva e de reconhecimento (FRASER, 2008). Assim, a injustiça social tem raízes na área socioeconômica, como nos padrões culturais de representação, necessitando assim de políticas que democratizem 0 acesso a educação superior, que proporcione a permanência dos menos favorecidos nesse nível de ensino.

Los grupos bidimensionalmente subordinados padecen tanto una mala distribución como un reconocimiento erróneo en formas en las que ninguna de estas injusticias es un efecto indirecto de la otra, sino que ambas son primarias y cooriginales. Por tanto, en su caso, no basta ni una política de redistribución ni una de reconocimiento solas. Los grupos bidimensionalmente subordinados necesitan ambas. (...) específicas de subordinación de estatus, que incluyen la estigmatización y la agresión física; la devaluación cultural, la exclusión social y la marginación política; hostilidad y menosprecio en la vida cotidiana y negación de los derechos, plenos y protecciones equiparables de los ciudadanos. Estas injusticias, daños prototípicos de reconocimiento erróneo, sólo pueden remediarse mediante una política de reconocimiento. (FRASER, 2008, p.91).

Nesse sentido as ações afirmativas atuam como redistribuição dos conhecimentos socialmente construídos, como na perspectiva de reconhecimento, já que reconhece que existem grupos que estão vivenciando processos excludentes de acesso ao capital cultural.

A categoria de equidade social em um contexto de desigualdade social torna-se um debate inócuo, pois se acredita que a igualdade só ocorre quando os sujeitos estão no mesmo patamar de condições para competir, quando não estão, se faz necessário flexibilizar mecanismos formais, com o intuito de proporciona um processo justo. Corrobora com essa compreensão Morosini (2009) que diz que a equidade tem relação com a intensidade que os educandos podem beneficiar-se da educação, da formação, do acesso a oportunidades, acompanhamentos, produzindo assim resultados.

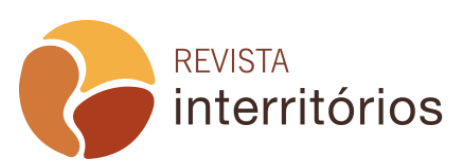

Interritórios | Revista de Educação

Universidade Federal de Pernambuco, Caruaru, BRASIL | V.6 N.12 [2020] 
Equidade de acesso é o fator inicial de discussão quando se fala em Educação Superior, no entanto ela só ocorre a partir do momento que todos têm as mesmas condições de competir, isto é, quando o ensino anterior ao Ensino Superior é oferecido em qualidades iguais a todos, proporcionando então, uma competição justa. $\mathrm{O}$ mesmo ocorre em relação à equidade de progresso e resultado no Ensino Superior. (FELICITTI e MOROSINI, 2009, p.11).

Ora, o público das ações afirmativas conforme a Lei ํo 12.711 de 2012, para além do recorte ético-racial, também deve possuir baixa condição socioeconômica e ser de origem de escola pública, o que denota que os sujeitos não partem das mesmas posições, para que se utilizar o princípio do mérito, sendo necessária a flexibilidade tendo em vista a inclusão de segmentos subrepresentados.

A partir dos pressupostos teóricos sobre democratização, justiça social e equidade, se buscou situar as ações afirmativas, para que em seguida, fazermos a revisão literária em teses e dissertações defendidas na UFPB.

\section{Caminhos da pesquisa e seus achados}

Inicialmente, a partir das informações contidas no site da UFPB e Plano de Desenvolvimento Institucional 2019-2023, situamos a história da universidade e sua estrutura. A UFPB foi criada pela Lei Estadual no 1366 de 02 de dezembro de 1955, por meio da conexão das escolas superiores, sua federalização veio a ocorrer em 1960, ano em que recebeu o nome de Universidade Federal da Paraíba, com uma estrutura multicampi nas cidades de João Pessoa e Campina Grande, ainda na década de 1960 incorporou a sua estrutura campus nas cidades de Areia e Bananeiras. Cabe ressaltar que nesse processo:

$\mathrm{Na}$ medida em que a federalização de escolas superiores resultou no processo de aglutinação de instituições isoladas, em seus primórdios essas universidades não conseguiam articular de maneira orgânica as atividades de ensino e pesquisa. Em 1964 o país dispunha de 35 universidades, a grande maioria pertencente ao setor; no entanto, o sistema universitário no seu conjunto permanecia sem tradição de pesquisa. (MARTINS in FERREIRA e MOREIRA, 2001, p. 299).

Nos anos de 1970 e 1980 as atividades de ensino, pesquisa e extensão avançaram de maneira significativa, incorporando mais três campi, nas cidades de Sousa, Cajazeiras e Patos. Devido aos custos operacionais elevados, optou-

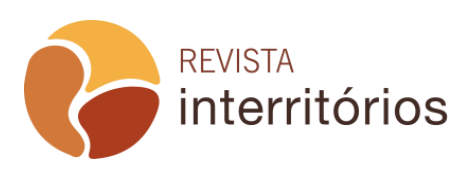

Interritórios | Revista de Educação

Universidade Federal de Pernambuco, Caruaru, BRASIL | V.6 N.12 [2020] 
se em 2002 pelo desmembramento da UFPB, por meio da Lei no 10.419 de 2002, foi criada a Universidade Federal de Campina Grande que ficou com os campi de Campina Grande, Cajazeiras e Patos.

A UFPB ficou composta pelos campi de João Pessoa, Areia e Bananeiras e em 2006, pela política de interiorização e expansão do acesso à educação superior foi criado um novo campus, abrangendo as cidades de Mamanguape e Rio Tinto.

A Universidade possui sete pró-reitorias: Pró-Reitoria administrativa, PróReitoria de Extensão e Assuntos Comunitários, Pró-Reitoria de Promoção e Assistência ao Estudante, Pró-Reitoria de Graduação, Pró-Reitoria de Gestão de Pessoas, Pró-Reitoria de Planejamento e Pró-Reitoria de Pós-Graduação.

No que diz respeito, a infraestrutura física, considerando os quatro campi que compõem a UFPB, as instalações acadêmicas disponíveis nos 16 Centros de Ensino totalizam 724 salas de aula, 50 auditórios, 18 bibliotecas, 537 laboratórios, 92 salas de departamentos, 868 salas para docentes, 130 salas de coordenações e 78 áreas de lazer.

No PDI 2019-2023 consta a missão da universidade:

Gerar e difundir conhecimento e inovação por meio de ensino, pesquisa e extensão para contribuir com o desenvolvimento da sociedade de forma sustentável, assegurando uma educação pública, gratuita, inclusiva, equitativa e de qualidade. (UFPB, 2019, p. 38).

Partindo desse lócus, nossa investigação pretende realizar uma revisão literária cujo "objetivo é revisar e relatar em maior detalhe um leque específico de estudos anteriores, diretamente dirigidos a seu provável tema de estudo, método e fonte de dados." (YIN, 2016, p.55). A revisão literária é uma possibilidade para o pesquisador iniciar o processo de investigação de temas que suscitam sua curiosidade, a fim de que este possa identificar os estudos de problemáticas que pretende investigar posteriormente. A relevância desse tipo de estudo encontra-se em fornecer um panorama das pesquisas que já foram realizadas e as lacunas que poderão tornar-se problemas de pesquisa futuros, 0 que contribui para o processo de construção do conhecimento e auxilia pesquisadores na definição de objetivos para pesquisa.

Como primeiro passo para este estudo realizamos uma pesquisa no site da biblioteca de teses e dissertações da UFPB, nossa escolha por trabalhos científicos em nível de Pós-Graduação se deu pelo fato de realizarmos o processo seletivo de doutorado em educação na instituição, bem como por 
contribuir com a construção do conhecimento a fim de identificar possíveis temas para trabalhos no campo da educação superior. A pesquisa foi realizada entre os meses de setembro e outubro de 2019, através dos descritores: "cotas" e "ações afirmativas". Não delimitamos ano e nem área do conhecimento, já que nosso intento inicial foi fazer um levantamento quantitativo dos trabalhos. Como resultado quantitativo, pela busca desses descritores em dissertações, tivemos o quantitativo de 77 produções, entre os anos 2000 a 2019, sendo as maiores áreas de concentração as ciências sociais aplicadas e a educação, já com relação às teses tivemos 26 estudos, sendo a maioria destes nas áreas de educação e psicologia.

Observamos que o número de publicações sobre as ações afirmativas é bem escasso, levando em consideração o tempo de dezenove anos de produções acadêmicas. Após, este levantamento preliminar, verificamos por meio da leitura de títulos e resumos, os trabalhamos que tratava das cotas como mecanismo de acesso à educação superior, logo tivemos uma queda acentuada no número dos trabalhamos, sendo que para o nosso processo investigativo, temos: 09 dissertações e 03 teses. Este resultado é relevante, pois aponta para a escassez de estudos na área, mesmo depois de instituída a Lei oㅜ 12.711 de 2012. Trazemos um quadro síntese do ano das produções:

Quadro 1- Ano de publicação das dissertações e teses sobre cotas na UFPB

\begin{tabular}{|l|l|l|l|l|l|l|}
\hline 2008 & 2012 & 2013 & 2014 & 2015 & 2016 & 2017 \\
\hline 01 & 02 & 02 & 04 & 01 & 01 & 01 \\
\hline
\end{tabular}

Fonte: Primária.

Por meio desse levantamento quantitativo, suscitou o intento de investigar a respeito da adoção de cotas na UFPB, já que percebemos escassos trabalhos em nível de mestrado e doutorado. Encontramos, através de busca online o Dossiê Ações Afirmativas na UFPB: a longa década da democratização inconclusa no ensino superior (1999-2012), publicado em 2013, e então começamos a nos debruçar nas informações contidas no documento. Nesse sentido, as informações contidas, foram analisadas a partir do Ciclo de Políticas em Ball (BOWE et al., 1992). O ciclo de políticas propõe a análise das políticas educacionais a partir de contextos que estão inter-relacionados e atuam de forma dialética.

Com base em Manairdes (2006) no contexto de influência, podemos observar as arenas em disputas, que marcaram a trajeto das ações afirmativas na UFPB, conforme análise do supracitado dossiê, observamos que as discussões partem de movimentos da sociedade, como a Pastoral do Negro, 0 Movimento Negro da Paraíba e grupos de capoeira, entre os anos de 1999 a 
2002. O debate chega a Pró-Reitoria de Graduação entre os anos 2007 a 2009, a então Pró-Reitoria elabora um projeto sobre cotas na UFPB e envia aos conselhos de centros, para que estes emitam sua opinião, sendo que a maioria destes se posicionou contrária à instituição de cotas na UFPB, excetuando o Centro de Educação. O que denota as disputas que estão na sociedade para adoção de políticas inclusivas, que faz com que o debate atravesse a universidade, mas que apresenta processos de negação de políticas inclusivas dentro da instituição.

Em 2009 o Ministério Público Federal encaminha uma recomendação no 09 que solicita a UFPB que esta emita parecer para implantação do sistema de reserva de vagas, sob a alegação que a universidade é uma das raras no Brasil que não adotou nenhum tipo de mecanismo de ação afirmativa. Assim, podemos concluir que o processo de reserva de vagas na UFPB foi marcado por embates e pressões externas, que solicitavam o posicionamento da universidade e de sua função social de incluir segmentos da classe desfavorecida na educação superior.

A modalidade de reserva de vagas iniciou-se no antigo Processo Seletivo Seriado (PSS), no ano de 2011, na ocasião foram ocupadas 1447 vagas por alunos cotistas, após o ingresso desses estudantes, houve a solicitação do acompanhamento destes e por políticas de permanência, como nosso objetivo não é explanar a respeito da permanência dos alunos cotistas, passaremos a dá continuidade a revisão literária, mas salientamos a importância de investigações no campo do acesso, permanência e êxito dos alunos cotistas na instituição.

Nesse segundo momento, organizamos as produções por ano, tipo de trabalho, área do conhecimento, logo após, por meio da leitura dos estudos, destacaremos os principais assuntos tratados, autores e abordagens de procedimentos teórico-metodológico.

Quadro 2- Dissertações e teses sobre cotas na UFPB 2008-2017

\begin{tabular}{|l|l|l|l|}
\hline Autor (a) & Título do trabalho & $\begin{array}{c}\text { Tipo de } \\
\text { estudo }\end{array}$ & $\begin{array}{c}\text { Ano/ Área do } \\
\text { conhecimento }\end{array}$ \\
\hline $\begin{array}{l}\text { lara Santos da } \\
\text { Cruz }\end{array}$ & $\begin{array}{l}\text { A cor da UFPB: um retrato racial } \\
\text { dos estudantes da Universidade } \\
\text { Federal da Paraíba em 2003 }\end{array}$ & Dissertação & $\begin{array}{l}\text { 2008/Serviço } \\
\text { Social }\end{array}$ \\
\hline $\begin{array}{l}\text { Talita Leite } \\
\text { Tavares }\end{array}$ & $\begin{array}{l}\text { Repertórios discursivos sobre } \\
\text { cotas raciais e suas implicações } \\
\text { no tratamento de alunos cotistas }\end{array}$ & Dissertação & 2012/Psicologia \\
\hline
\end{tabular}




\begin{tabular}{|c|c|c|c|}
\hline $\begin{array}{l}\text { Nayara Tatiana } \\
\text { Santos da Costa }\end{array}$ & $\begin{array}{l}\text { Do debate à implementação: a } \\
\text { versão não oficial da adoção das } \\
\text { cotas raciais na UFPB }\end{array}$ & Dissertação & 2012/Educação \\
\hline $\begin{array}{l}\text { Clóvis Pereira da } \\
\text { Costa Júnior }\end{array}$ & $\begin{array}{l}\text { Do branqueamento às cotas } \\
\text { raciais: conhecimento histórico e } \\
\text { memória para a tomada de } \\
\text { posição }\end{array}$ & Dissertação & 2013/Psicologia \\
\hline $\begin{array}{l}\text { Leila Santos de } \\
\text { Mesquita }\end{array}$ & $\begin{array}{l}\text { O acesso do surdo ao ensino } \\
\text { superior: limites e avanços das } \\
\text { políticas educacionais de inclusão }\end{array}$ & Dissertação & 2013/Educação \\
\hline $\begin{array}{l}\text { Maria Luciene } \\
\text { Ferreira Lima }\end{array}$ & $\begin{array}{l}\text { Políticas públicas no ensino } \\
\text { superior: ações afirmativas na } \\
\text { UFPB }\end{array}$ & Dissertação & $\begin{array}{l}\text { 2014/Direitos } \\
\text { humanos, } \\
\text { cidadania e } \\
\text { políticas } \\
\text { públicas }\end{array}$ \\
\hline $\begin{array}{l}\text { Charles de Sousa } \\
\text { Trigueiro }\end{array}$ & $\begin{array}{l}\text { Políticas afirmativas para pessoas } \\
\text { com deficiência e a efetividade do } \\
\text { princípio do pleno emprego: o } \\
\text { caso dos portadores de visão } \\
\text { monocular e surdez unilateral }\end{array}$ & Dissertação & 2014/Direito \\
\hline $\begin{array}{l}\text { Luciana Augusto } \\
\text { Barreto }\end{array}$ & $\begin{array}{l}\text { Pela graça da mistura: ações } \\
\text { afirmativas, discurso e identidade } \\
\text { negra no curso de direito em } \\
\text { universidades públicas } \\
\text { paraibanas }\end{array}$ & Tese & 2014/Educação \\
\hline $\begin{array}{l}\text { Luísa do Amparo } \\
\text { Carvalho }\end{array}$ & $\begin{array}{l}\text { Preconceito, identidade e } \\
\text { representações sociais: relações } \\
\text { intergrupais de estudantes } \\
\text { indígenas e não indígenas no } \\
\text { ambiente acadêmico }\end{array}$ & Tese & 2014/Psicologia \\
\hline $\begin{array}{l}\text { Nayara Katrine } \\
\text { Pinheiro }\end{array}$ & $\begin{array}{l}\text { As representações sociais sobre o } \\
\text { mérito: um estudo com } \\
\text { estudantes cotistas e não cotistas } \\
\text { da Universidade Federal do } \\
\text { Semiárido do Rio Grande do } \\
\text { Norte. }\end{array}$ & Dissertação & $\begin{array}{l}\text { 2015/Administra } \\
\text { ção }\end{array}$ \\
\hline $\begin{array}{l}\text { Sérgio Rodrigues } \\
\text { de Santana }\end{array}$ & $\begin{array}{l}\text { Informação étnico-racial no } \\
\text { âmbito dos programas de pós- } \\
\text { graduação em psicologia }\end{array}$ & Dissertação & $\begin{array}{l}\text { 2016/Ciência da } \\
\text { informação }\end{array}$ \\
\hline
\end{tabular}




\begin{tabular}{|l|l|l|l|}
\hline $\begin{array}{l}\text { Nayara Tatiana } \\
\text { Costa }\end{array}$ & $\begin{array}{l}\text { A democratização nos cursos de } \\
\text { elevado prestígio social na UFPB: } \\
\text { acesso e permanência dos } \\
\text { estudantes cotistas }\end{array}$ & Tese & 2017/Educação \\
\hline
\end{tabular}

Fonte: Primária.

Vemos que os trabalhos se concentram nas áreas da educação e psicologia, mas também aparecem no serviço social, direito, ciências da informação, administração e direitos humanos. No que se referem ao campo da educação os estudos tem enfocado o acesso e a permanência dos estudantes, com ênfase em cursos de elevado prestígio social. Nestes estudos o conceito de cotas encontra-se ligado ao de acesso das minorias à educação superior, como mecanismo de ingresso e fator de mobilidade social, com ênfase nas categorias de capital cultural; campo e habitus, descritas por Bordieu (2015). Outro conceito apresentado é a representação coletiva (DURKHEIM, 1994) como forma de difundir ideias e pensamentos, ressaltando o papel da universidade como unidade de construção do saber e sua responsabilidade para a comunidade.

No percurso metodológico as pesquisas em educação utilizaram a abordagem qualitativa, quanto às formas de coletas de dados, foram utilizados o questionário e as entrevistas semiestruturadas, no que diz respeito à análise dos dados, a análise de Bardin (1977), como também o ciclo de políticas de Ball, que enfatiza que estamos em um campo de arenas como políticas interrelacionadas em que devemos levar em consideração os espaços global e local, nos domínios da globalização. (BALL et al., 1992).

No campo da psicologia os estudos possuíram o objetivo de investigar o processo de expressões de preconceito e racismo a partir das teorias de representações sociais, relações intergrupais e identidade social, ancorados em autores, como: Braga e Campos (2012). Na trajetória metodológica os conteúdos discursivos elaborados a partir das memórias resgatadas dos participantes da pesquisa são utilizados com fonte de coleta de dados, bem como os questionários. No processo de sistematização dos dados vimos que é comum a utilização de softwares, como Alceste, quanto à análise dos dados o autor utilizado é Bardin (1977).

O estudo na área das ciências da informação versa sobre elementos históricos e culturais de grupos étnico-raciais abarcados pelas as ações afirmativas. O método utilizado no trabalho é o método fenomenológico, que consiste em demonstrar e investigar a essência dos fenômenos, a abordagem utilizada possui natureza quantitativa e qualitativa e para o tratamento dos dados foi utilizado o software Alceste. 
A dissertação no campo da administração teve o objetivo de investigar sobre as representações sociais sobre o mérito dos alunos cotistas e não cotistas, para a fase da coleta de dados foram realizadas entrevistas semiestruturadas e os resultados foram analisados pela proposta de Bardin (1977).

O estudo no campo do direito teve a finalidade de refletir e analisar a jurisprudência e a normativa de efetivação do princípio do pleno emprego em consonância com as orientações internacionais de direitos humanos para as pessoas com deficiência com o foco na inserção no mundo do trabalho, no que se refere ao percurso metodológico foi utilizada pesquisa documental.

$\mathrm{Na}$ dissertação no campo dos direitos humanos, cidadania e políticas públicas o objetivo foi discutir o processo de implantação da modalidade de ingresso por reserva de vagas para o acesso aos cursos de graduação na UFPB, a partir das diretrizes curriculares e as propostas pedagógicas dos cursos de direito, medicina, engenharia e pedagogia com 0 foco nas mudanças significativas nas práticas pedagógicas. A metodologia possui a natureza quantiqualitativa a partir da análise documental.

A dissertação na área do serviço social tratou de investigar a implantação de cotas sociais e raciais em universidades do Rio de Janeiro, em 2003. O trabalhou buscou fazer um paralelo sobre a necessidade da implantação do sistema de reserva de vagas na UFPB, como também a partir de fontes secundárias, fornecidas pela Pró-Reitoria de Graduação, conhecer a cor da UFPB, sendo este recorte racial feita a partir de cada curso de graduação.

Apresentado os debates que podem ser encontrados nas dissertações e teses sobre ações afirmativas defendidas na UFPB, passaremos a tecer comentários a respeito de outras reflexões que permeiam o campo de cotas, as lacunas encontradas a partir desta revisão e análises que podem contribuir para o processo de investigação científica de outros trabalhos.

Com a aprovação da Lei 12.711 de 2012, a modalidade de reserva de vagas passa ser garantia estabelecida por força jurídica, logo se faz necessário o foco em ações de permanência desses estudantes, evitando assim a evasão e o trancamento dos cursos. Do acesso à conclusão do curso, existe um longo caminho que é o processo de permanência, de modo que novos desafios emergem para proporcionar a qualidade do acesso/permanência/sucesso destes estudantes.

Nos termos de Jezine e Castelo Branco (2013), no centro desse debate, é preciso ter a clareza teórica e metodológica, pois não se pode avaliar o acesso dos estudantes em situação de desigualdade social, no ensino superior, como sinônimo de inclusão. Isso porque o significado da concepção de inclusão excede a ideia de acesso, promovido pelas políticas de expansão de vagas. 
O conceito de democratização encontra-se amplamente falseado do seu sentido original, haja vista que a democratização da educação só ocorre quando se está garantindo o acesso e a permanência em instituições públicas que funciona no tripé: ensino, pesquisa e extensão. Ao contrário, o que vemos em nossa sociedade é a mercantilização da educação, através das instituições privadas que funcionam baseadas no lucro, ou em outros termos a massificação do ensino pelo setor privado que detém $75 \%$ das matrículas, conforme dados do Censo de Educação Superior (2017).

Pois, sob a alegação da suposta democratização do ensino superior mercantiliza-se a educação, manifestando a contradição, ao menos, as ambiguidades e os paradoxos das políticas públicas de ideologia neoliberal. $O$ debate envolve toda a sociedade, uma vez que a expansão do ensino superior é uma antiga reivindicação dos movimentos sociais e estudantis, colocando na agenda a aversão a respeito da educação refletida como política pública ou como mercadoria acessível no mercado (SANTOS; FREITAS; GOMES, 2015).

Conforme Chauí (2003) devemos compreender a universidade pública sob uma nova perspectiva. A relação democrática entre Estado e universidade pública está sujeita ao nosso entendimento sobre o núcleo da República. Tal núcleo é o fundo público e a democratização deste fundo significa investi-lo não para garantir a acumulação e a reprodução do capital - que é o que preconiza o neoliberalismo com o chamado Estado mínimo e sim para garantir a concentricidade dos direitos sociais, entre os quais se encontra o direito à educação.

Ações afirmativas são políticas que alocam recursos em benefício de pessoas pertencentes a grupos discriminados e vitimados pela exclusão socioeconômica no passado ou no presente. As cotas são mecanismos que têm como objetivo enfrentar discriminações étnicas, raciais, religiosas, de gênero ou de casta, acrescendo a participação de minorias no processo político, no acesso a educação, saúde, emprego e renda, bens materiais, redes de proteção social e/ ou no reconhecimento cultural. (FERES JÚNIOR e DAFLON, 2014).

Vimos que existem trabalhos que têm abordado os fenômenos a partir de uma abordagem quanti-qualitativa, vale considerar as reflexões do professor Silvio Gamboa (1995), sobre pesquisas com o perfil quanti-qualitativa, a centralidade da pesquisa encontram-se em suas epistemologias e não em técnicas quantitativas e qualitativas, mas como estas técnicas estão articuladas com os métodos científicos. $O$ autor adverte para falsas dicotomias e dualismos, num reducionismo no âmbito de técnicas.

São lacunas encontradas o estudo a respeito de políticas de permanência, assistência estudantil e a inserção no mundo do trabalho dos alunos cotistas, como também o impacto das ações afirmativas na UFPB e o quê os estudantes 
cotistas têm pesquisado. Outra questão que merece destaque é a resolução da instituição no 58 de 2016, que trata sobre as ações afirmativas na pós-graduação, carecendo este tema de novos estudos analíticos.

\section{CONSIDERAÇÕES FINAIS}

Ao final, ressaltamos que os conceitos trabalhados pelos autores perpassaram pela democratização da educação superior, igualdade de acesso e permanência, política de cotas, equidade, mérito e representação social. Como resultados, trouxemos um panorama dos estudos sobre ações afirmativas, ressaltando temas para próximos trabalhos, além de reflexões a respeito das cotas na UFPB.

Diante do exposto e das sugestões para outros estudos, ressaltamos a avaliação da política de cotas, o acompanhamento das taxas de conclusão de curso e de evasão dos alunos cotistas, bem como o debate sobre ações afirmativas voltadas para a pós-graduação nas universidades, públicas e particulares. Acreditamos que conseguimos apresentar algumas lacunas para o avanço na produção do conhecimento científico.

O artigo contribuiu para o processo de construção do projeto de pesquisa para seleção de doutorado em educação da UFPB, em que alcançamos aprovação e vamos refletir sobre as ações afirmativas na pós-graduação nas universidades federais do nordeste, logo indicamos essa técnica para pesquisadores, que estão no processo de construção de problemas de pesquisa, bem como para a fundamentação teórica nos estudos.

\section{REFERÊNCIAS}

ARAUJO, Rafaela Santos Venâncio de. Globalização e política de cotas para ingresso na educação superior: análise da normativa de direitos humanos e de documentos Internacionais. 2016. 118p. Dissertação (Mestrado em Educação) - Universidade Federal da Paraíba, João Pessoa, 2016.

BALL, Stephen. Diretrizes Políticas Globais e Relações Políticas Locais em Educação. Currículo sem Fronteiras, v.1, n.2, p. 99-116, jul./dez./2001. Disponível em: www.curriculosemfronteiras.org 99. Acesso em: jul./2016. ISSN 1645-1384

BARDIN, Laurence. Análise de conteúdo. Lisboa: Edições 70, 1977.

BARRETO, Luciana Augusto. Pela graça da mistura: ações afirmativas, discurso e identidade negra no curso de direito em universidades públicas paraibanas. 2014. 202 f. Tese (Doutorado em Educação) - Universidade Federal da Paraíba, João Pessoa, 2014.

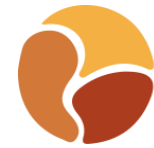


BOURDIEU, P.; PASSERON, J.-C. Os herdeiros: os estudantes e a cultura. Florianópolis: Editora da UFSC, 2015.

BORGES, Maria Creusa de Araújo. Princípios Norteadores de uma Educação em Direitos Humanos na Instituição Universitária. Verba Juris (UFPB), v. 7, p. 133-176, 2008.

BORGES, Maria Creusa de Araújo. A UNESCO e o Direito à Educação Superior. Cadernos ANPAE, v. 11, p. 1-15, $2011 \mathrm{a}$.

BORGES, Maria Creusa de Araújo. A Adoção do Sistema de Cotas como forma de Ingresso na Educação Superior Brasileira. In: JUNIOR, Luiz de Sousa; FRANÇA, Magna; FARIAS, Maria da Salete Barboza de. (Org.). Políticas de Gestão e Práticas Educativas: a qualidade do ensino. Brasília: Liber Livro, 2011b, v. 1, p. 143-156.

BRAGA, C. F.; CAMPOS, P. H. F. Representações sociais, situações

potencialmente comunicativas e conflito: o caso da reserva indígena Raposa Serra do Sol (2005-2009). Curitiba: Appris, 2012.

BRASIL. Lei de Diretrizes e Bases da Educação Nacional. Lei número 9.394, 20 de dezembro de 1996.

BRASIL. Constituição Federal de 1988. Promulgada em 5 de outubro de 1988. Disponível em http://www.planalto.gov.br/ccivil_03/constituicao/constituição.htm.Acessado em: 04 de dez. de 2019.

BRASIL. Lei no 12.711, de 29 de agosto de 2012. Dispõe sobre o ingresso nas universidades federais e nas instituições federais de ensino técnico de nível médio e dá outras providências. Diário Oficial da União, Brasília, 30 ago. 2012. Seção 1, p. 1.

BOWE, R.; BALL, S.; GOLD, A. Reforming education\& changing schools: case studies in policysociology. London: Routledge, 1992.

CHAUÍ, Marilena. A universidade pública sob nova perspectiva. Revista Brasileira de Educação. n. 24. set/dez 2003. Disponível em http://www.scielo.br/pdf/rbedu/n24/n24a02.pdf. Acesso em 09 ago. 2010

COSTA, Nayara Tatianna Santos da. A democratização nos cursos de elevado prestígio social na UFPB: acesso e permanência dos estudantes cotistas. 2017. Tese (Doutorado em Educação), Universidade Federal da Paraíba, João Pessoa-PB.

COSTA, Nayara Tatianna Santos da. Do debate à implementação: a versão não oficial da adoção das cotas raciais na UFPB.. 2012. 122 f. Dissertação (Mestrado em Educação) - Universidade Federal da Paraíba, João Pessoa, 2012.

COSTA JÚNIOR, Clóvis Pereira da. Do branqueamento às cotas raciais: conhecimento histórico e memória para a tomada de posição. 2013. 154f. Dissertação (Mestrado em Psicologia Social) - Universidade Federal da Paraíba, João Pessoa, 2013.

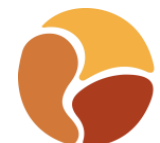


CRUZ, lara Santos da. A cor da UFPB: um retrato racial dos estudantes da Universidade Federal da Paraíba em 2003. 2008. 81 f. Dissertação (Mestrado em serviço Social) - Universidade Federal da Paraíba, João Pessoa, 2008.

CUNHA, L. A. A universidade reformada: o golpe de 1964 e a modernização do ensino superior. 2. ed. São Paulo: Editora UNESP, 2007.

DAFLON, V. T.; FERES JÚNIOR, J.; CAMPOS, L. A. Ações afirmativas raciais no ensino superior público brasileiro: um panorama analítico. Cadernos de Pesquisa, v. 43, n. 148 p. 302-327, 2014. Disponível em: http://www.scielo.br/pdf/cp/v43n148/15.pdf. Acesso em: 14 dez. 2015.

DURKHEIM. Emile. Representações individuais e representações sociais. In: DURKHEIM. Emile. Sociologia e Filosofi a. São Paulo: Ícone, 1994. p. 9-54.

FELICETTI, V. L., MOROSINI, M. C. Equidade e iniquidade no ensino superior: uma reflexão. Ensaio, Rio de Janeiro, v. 62, p. 9-24, 2009.

FERES JÚNIOR., João. Comparando justificações das políticas de ação afirmativa: Estados Unidos e Brasil". Estudos Afro-Asiáticos, v. 29, n. 1-3, p. 63-84. 2007.

FRASER, Nancy. Escalas de justicia, Barcelona, Herder.(2008)

GAMBOA, Sílvio Sanchez. Quantidade-qualidade: para além de um dualismo técnico e de uma dicotomia epistemológica. In: SANTOS FILHO, José Camilo; GAMBOA, Sílvio Sanchez (Org.). Pesquisa educacional: quantidade-qualidade. São Paulo: Cortez, 1995.

IBGE. Censo de Educação Superior de 2018. Acesso em: 15 de abril de 2020. Disponível em:

http://download.inep.gov.br/educacao_superior/censo_superior/documentos/2019/apre sentacao_censo_superior2018.pdf.

JEZINE, Edineide. O debate da temática da política de educação superior. IN: JEZINE, Edineide; CASTELO BRANCO, Uyguaciara Veloso; NAKAMURA, Paulo Hideo.

Políticas de Acesso à educação superior e os desafios da inclusão social. João Pessoa-PB: Editora da UFPB, 2015.

JEZINE, Edineide. Políticas de educação superior: os desafios da inclusão, acesso e permanência no contexto das Universidades Federais. IN: JEZINE, Edineide; CASTELO BRANCO, Uyguaciara Veloso; NAKAMURA, Paulo Hideo. Políticas de Acesso à educação superior e os desafios da inclusão social. João Pessoa-PB: Editora da UFPB, 2015.

LIMA, Maria Luciene Ferreira. Políticas públicas no ensino superior: ações afirmativas na UFPB. 2014. 152 f. Dissertação (Mestrado em Direitos Humanos) - Universidade Federal da Paraíba, João Pessoa, 2014.

LÜDKE, Menga \& ANDRÉ, Marli E. D. Pesquisa em educação: abordagens qualitativas. São Paulo: EPU, 1986. 
MAINARDES, Jefferson. Abordagem do Ciclo de Políticas: uma contribuição para a análise de políticas educacionais. Educ. Soc., Campinas, vol. 27, n. 94, p. 47-69, jan./abr. 2006.

MESQUITA, Leila Santos de. O acesso do surdo ao ensino superior: limites e avanços das políticas educacionais de inclusão. 2013. 92 f. Dissertação (Mestrado em Educação) - Universidade Federal da Paraíba, João Pessoa, 2013.

MOROSINI, M. C. Qualidade universitária: isomorfismo, diversidade e equidade. Interface, Botucatu: UNESP, 2001.

MOROSINI, M. C. Qualidade da educação superior: tendências deste século. Estudos em avaliação educacional. São Paulo: FGV, 2009.

NEABI/UFPB. Dossiê Ações Afirmativas na UFPB: a longa década da democratização inconclusa no ensino superior (1999-2012). João Pessoa: NEABI/CCHLA, 2013.

ROSEMBERG, Fúlvia. AÇÃO AFIRMATIVA NO ENSINO SUPERIOR BRASILEIRO: PONTOS PARA REFLEXÃO. Cadernos Pagu. (31), julho-dezembro de 2008:419-437.

Organização das Nações Unidas para a Educação, a Ciência e a Cultura (UNESCO). (2016). Repensar a educação: rumo a um bem comum mundial? Brasília, DF. Recuperado de http://unesdoc.unesco.org/images/0024/002446/244670POR.pdf

PATATAS, Luisa do Amparo Carvalho. Preconceito, identidade e representações sociais: relações intergrupais de estudantes indígenas e não indígenas no ambiente acadêmico. 2014. 219 f. Tese (Doutorado em Psicologia Social) - Universidade Federal da Paraíba, João Pessoa, 2014.

SANTANA, Sérgio Rodrigues de. Informação étnico-racial no âmbito dos programas de pós-graduação em psicologia. 2016. 124 f. Dissertação (Mestrado em Ciência da Informação) - Universidade Federal da Paraíba, João Pessoa, 2016.

SANTOS, Boaventura de Souza. A universidade no século XXI: para uma reforma democrática e emancipatória da universidade. São Paulo: Cortez, 2004.

SANTOS G. dos; FREITASL. O.; GOMESC. L. EMANCIPAÇÃO E A EXPANSÃO RECENTE DA EDUCAÇÃO SUPERIOR NO BRASIL:. Ser Social, v. 17, n. 37, p. 368389, 1 jun. 2016.

SANTOS, Jocélio Teles dos. Ações afirmativas e educação superior no Brasil: um balanço critico da produção. R. bras. Est. pedag., Brasília, v. 93, n. 234, [número especial], p. 401-422, maio/ago. 2012.

SERAFIM, Nayara Katryne Pinheiro. As representações sociais sobre o mérito: um estudo com estudantes cotistas e não cotistas da Universidade Federal do Semiárido do Rio Grande do Norte. 2015. 139 f. Dissertação (Mestrado em Administração) Universidade Federal da Paraíba, João Pessoa, 2015.

TAVARES, Talita Leite. Repertórios discursivos sobre cotas raciais e suas implicações no tratamento de alunos cotistas. 2012. 162 f. Dissertação (Mestrado em Psicologia Social) - Universidade Federal da Paraíba, João Pessoa, 2012.

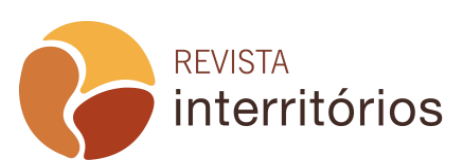

Interritórios | Revista de Educação

Universidade Federal de Pernambuco, Caruaru, BRASIL | V.6 N.12 [2020] 
TRIGUEIRO, Charles de Sousa. Políticas afirmativas para pessoas com deficiência e a efetividade do princípio do pleno emprego: o caso dos portadores de visão monocular e surdez unilateral. 2014. 100 f. Dissertação (Mestrado em Ciências Jurídicas) Universidade Federal da Paraíba, João Pessoa, 2014.

UNIVERSIDADE FEDERAL DA PARAÍBA. Resolução no 58 de 2016 dispõe sobre ações afirmativas na Pós-graduação Stricto Sensu na UFPB para candidatos autodeclarados e oriundos da população negra, povos indígenas, povos e comunidades tradicionais e pessoas com deficiência.

UNIVERSIDADE FEDERAL DA PARAÍBA. Aprovação do Plano de Desenvolvimento Institucional 2019-2013. Acesso em 15 de abril de 2020. Disponível em:

http://www.proplan.ufpb.br/proplan/contents/documentos/pdi/apresentacao-pdi-20192023.pdf/view.

YIN, R. K. Pesquisa qualitativa do início ao fim. Porto Alegre: Penso; 2016. 